\title{
REFLEXÕES SOBRE A INTERPRETAÇÃO E A SISTEMATIZAÇÃO DA LITERATURA
}

\author{
Leonardo Pinto de Almeida
}

\begin{abstract}
Resumo
Este artigo analisa as vicissitudes da captura do objeto literário feita pela cultura e pela crítica especializada. Apontamos que a interpretação e a sistematização são modos reacionários do uso da literatura, ajudando a restringir a liberdade suscitada pela experiêncialiterária. Concluímos que, a cultura institucionalunifica e enquadra as obras literárias, o comércio apresenta um papel pasteurizador da transgressão literária e uma parte da crítica literária despotencializa a obra. Mas também deixamos claro que existem modos de crítica que fogem a este caráter despotencializador da obra, fazendo que a obra seja o que ela é: um espaço intenso de experimentação.
\end{abstract}

Palavras-Chave: literatura; interpretação; sistematização; leitura.

\section{REFLECTIONS ON THE INTERPRETATION AND THE SYSTEMATIZATION OF LITERATURE}

\begin{abstract}
We analyze the capture of the literary object made by culture and by specialized critical. We pointed the interpretation and the systematization is a reactionary way of use of literature, helping to restrict the freedom excited for literary experience. We conclude that, the institutional culture unifies and fits the literary compositions, the commerce presents a pasteurizer role of the literary trespass and a part of literary critique unpowered the workmanship. But we thought that exist many critique ways that run away to this unpowerment character of the workmanship, making that to be what it is: an intense space of experimentation.
\end{abstract}

Keywords: literature; interpretation; systematization; reading.

\footnotetext{
^ Psicólogo, mestre em Psicologia pela Universidade Federal Fluminense, doutor em Psicologia pela Pontifícia Universidade Católica do Rio de Janeiro com estágio sanduíche no Centre de Recherche sur la Lecture Littéraire na Université de Reims Champagne-Ardenne (França). Realizou o pósdoutorado no Departamento de Psicologia da PUC - Rio (2008), sob o financiamento do CNPq (bolsa PDJ/CNPq). Instituição PUC - Rio. Departamento de Psicologia. Endereço: PUC-Rio Depto. de Psicologia (PSI) - R. Marquês de São Vicente, 225 Cardeal Leme, 2o. andar. Gávea. CEP: 22451-900. Rio de Janeiro - RJ - Brasil

E-mail: leonardo.p.almeida@gmail.com.br, tazaime@hotmail.com
} 
Este artigo objetiva traçar um modo de compreensão acerca da dinâmica da interpretação e da sistematização da literatura feita pela cultura institucional ${ }^{1}$ e pela crítica literária.

A interpretação da obra é produto da dialetização dos elementos da experiência, decompondo-a em componentes supostamente explicativos da experiência literária. Este movimento separa estes componentes que atuam conjuntamente no seio da experiência para usá-los como unidades transcendentes explicativas da obra, como por exemplo, a vida do autor, o estilo da escrita, o gênero literário.

Já a sistematização dos elementos constrói um conjunto de explicações que direcionam a apropriação da literatura. Ela aponta para um ordenamento do universo literário por meios de panoramas totalizantes.

Enquanto, a interpretação esquadrinha a obra, construindo uma teia explicativa de elementos separados, a sistematização encaixa a obra em conjuntos totalizados. Ambos movimentos ajudam na imposição de sentido construído pelos vetores institucionalizantes da cultura.

Goulemot (2001) assinala, em "Da leitura como produção de sentidos", que o aspecto institucional da cultura tem como característica construir uma predisposição direcionada para a recepção do texto. Ela aponta também que cada época e cada cultura inventam seus próprios códigos e modelos que objetivam conduzir as práticas em torno do universo dos livros.

Em L'Entretien Infini, Blanchot (1969) sublinha a controversa natureza da obra literária por possuir um caráter fugidio. Contudo, será evidentemente por isso, que ele marcará a violência da cultura em seus movimentos de captura da literatura, tecidos através das idéias de unidade, unificação, totalidade e identidade.

Estes movimentos partem de um processo de totalização dos elementos dispersos no universo cultural. Daí, sua característica de organização deste universo de valores humanos por um processo de totalização, que se baseia na identificação de elementos dispersos a partir de valores pré-concebidos. Este processo os enquadra em um movimento que os seleciona e os convoca a fazer parte de um todo: o conjunto cultural.

A cultura toma as obras em seu universo unificado. As obras literárias são absorvidas como coisas. Assim, poderíamos afirmar que a cultura é capaz de unificar as obras, através de um campo semiótico determinado, retirando delas sua potência criadora e transformadora. Daí, pensarmos, junto a Blanchot (1969), que tanto a idéia de obra, no contexto deste aspecto institucionalizante da cultura, quanto a de obra-prima e, mesmo, a de autoria, são operadores da manutenção do universo cultural.

A cultura, então, se aliaria ao processo de essencialização da obra e da mitologização do autor. Este processo absorve as obras literárias para construção da unidade e do panorama cultural e a restituição das identidades perdidas no turbilhão da experiência. 
Neste mesmo texto, Blanchot (1969) afirma que este processo ligado à constituição do conjunto, da unidade, do todo, do panorama cultural seria cumulativo, visando apenas à obra como resultado positivo de um trabalho de significação e de conteúdo representado nela e através dela. Por este motivo, poderíamos acrescentar que a figura autoral seria cara à cultura, como índice discursivo e agente produtivo da obra, pois seria ele o sujeito que trabalha as idéias mediante a escrita, sendo a obra o produto do seu labor. Esta idéia de trabalho da escrita seria uma das noções fundantes da "mitologia autoral".

Contudo, é curioso pensarmos que este movimento de enquadramento das obras literárias ao conjunto dos tesouros culturais muito se assemelha a uma grande biblioteca virtual, se levarmos em conta que as bibliotecas têm por função primeira, a de organização e acúmulo de bens: livros e documentos.

Assim sendo, a cultura em seu trabalho de enquadramento das obras literárias em seu todo se aproveita de conceitos importantes, como por exemplo, o autor e a obra-prima, para a manutenção da unificação e do conjunto dos tesouros da cultura. Estes conceitos seriam elementos naturalizados, reificados e separados da experiência literária para impor uma ordenação da apropriação dos textos literários.

Quando Blanchot (1969, p. 587) afirma que "o homem da cultura é feliz", não deixamos de pensar o quanto este processo de unificação das obras literárias tem um caráter de alívio frente à enxurrada de obras escritas que se proliferam ao longo de nossa história. A felicidade e a cultura estão associadas, deste modo, por causa da tranqüilidade gerada pelo processo de enquadramento de elementos dispersos em uma visão panorâmica que proporciona a familiarização. O "homem da cultura", aqui marcado, se aproximaria em certo aspecto àquilo que Kundera (1993, p. 210) chamou de "homem de convicção":

[...] mas o que é uma convicção? É um pensamento que parou, que se congelou, e o homem de convicção é um homem limitado; o pensamento experimental não deseja persuadir mas inspirar; inspirar um outro pensamento, pôr em movimento o pensar; é porque um escritor deve sistematicamente desistematizar o pensamento, dar chutes na barricada que ele ergueu em volta de suas idéias.

A convicção seria então o pensamento congelado por idéias que se querem verdadeiras e sem controvérsias. O "homem de convicção" é um "homem limitado" pelas verdades que defende e acredita: seus sistemas de valores direcionam suas condutas frente à vida. O "homem da cultura" e o "homem de convicção" se aproximam, devido ao fato de que ambos têm suas condutas limitadas por um sistema de valor. A cultura é o sistema de valor que possibilita a satisfação e o alívio do "homem da cultura", frente a esta experiência que pode ser tão desestabilizadora que é a experiência literária. 
Este trecho de Les Testaments Trahis (KUNDERA, 1993) mostra este confronto entre o caráter fugidio da literatura sua a-sistematicidade constitutiva e a convicção e a cultura que querem limitar a experiência, se baseando em um sistema de conceitos e valores pré-concebidos.

Este movimento de unificação se caracteriza pela captura desta atividade transgressiva que é a literatura, compondo-se a partir de sentimentos de alívio, tranqüilidade, satisfação e poder. Nietzsche (2006, p. 43), em Crepúsculo dos idolos, em um aforismo intitulado muito propriamente de "Explicação psicológica para isso tudo" esclarece alguns elementos importantes para nossa reflexão:

\begin{abstract}
Fazer remontar algo desconhecido a algo conhecido alivia, tranqüiliza, satisfaz e, além disso, proporciona um sentimento de poder. Com o desconhecido há o perigo, o desassossego, a preocupação nosso primeiro instinto é eliminar esses estados penosos. Primeiro princípio: alguma explicação é melhor que nenhuma. Tratando-se, no fundo, apenas de um querer livrar-se de idéias opressivas, não se é muito rigoroso com os meios de livrar-se delas: a primeira idéia mediante a qual o desconhecido se declara conhecido faz tão bem que é "tida por verdadeira". Prova do prazer ("da força") como critério da verdade. O impulso causal é, portanto, condicionado e provocado pelo sentimento de medo.
\end{abstract}

Este aforismo aponta para a dinâmica psicológica deste "homem da cultura", que busca a satisfação nos conceitos explicativos da obra e, também para este aspecto da cultura que objetiva enquadrar obras em planos horizontais de conjunto.

Em relação a estes movimentos da cultura, o pensamento de Kundera sobre os mass media se aproxima à reflexão blanchotiana sobre a totalização dos bens culturais. Em $L$ 'art du roman, Kundera (1986) salienta uma contraposição entre o espírito dos mass media e o espírito do romance, mostrando que a unificação das obras por parte da cultura é um trabalho redutor da experiência literária. Este trabalho enjaula a potência literária sob as grades dos conceitos de autoria e de obra. "O romance (como toda a cultura) se encontra de mais a mais nas mãos das mídias; estas, sendo agentes da unificação da história planetária, ampliando e canalizando o processo de redução" (KUNDERA, 1986, p. 29).

A cultura, assim, por meio de seus "agentes de unificação da história planetária", reduz o sentido das obras literárias a partir de arquétipos dormentes, clichês e explicações simplificadoras da experiência literária. Os mass media esta parte da cultura institucional se contrapõem ao espírito romanesco, devido à sua vontade de verdade, controle e domínio sobre o objeto literário.

Como podemos pensar, a crítica literária entendida aqui, como um conjunto de explicações acerca da literatura ajudaria, de certo modo, a manutenção deste movimento da cultura. No entanto, não poderíamos afirmar que a crítica seria, em seu todo, uma mera mantenedora das vias da cultura, pois nela também encontramos forças criadoras e opressoras atuando em seus interstícios. 
Em A função da crítica, Eagleton (1991, p. 1) salienta que atualmente a crítica literária “ou faz parte do ramo de relações públicas da indústria literária, ou é uma questão inteiramente interna às academias". Neste caso, a crítica estaria associada às searas jornalísticas que impulsionam às vendas dos livros e às discussões acadêmicas que estão associadas às lutas pelo monopólio do sentido.

Em $L$ 'art du roman, Kundera (1986) coloca que com o surgimento do romance, como afirmam Blanchot (1987), Barthes (1984), Foucault (2001) e Brunn (2001), o escritor desaparece através da escrita da obra. No entanto, ele acrescenta que, no movimento dos mass media, há uma inversão destes fatores, fazendo a obra desaparecer atrás da figura autoral. A obra seria um epifenômeno da vida do autor, sendo esta crença, uma das mais importantes na fundação da "mitologia autoral" que objetiva explicar a obra por seu autor.

Não é fácil hoje onde tudo, mesmo algo que não tenha muita importância, deva passar pela cena insuportavelmente iluminada dos mass media que, contrariamente à intenção de Flaubert, fazem desaparecer a obra atrás da imagem de seu autor (KUNDERA, 1986, p. 190).

A cultura ilumina com sua luz ofuscante a obra e seu autor para dar consistência à importância dada por ela em seu movimento de captura. Este texto de Kundera (1986) indica um ponto importante: ao tornar-se um homem público, o escritor traz um problema para a recepção de sua obra literária. Os mass media, ao mesmo tempo, que esclarecem, ocultam a importância da obra ao se comprometerem à esclarecê-la pela vida e pela personalidade de seu escritor. Este esclarecimento oblitera a experiência literária, por se ater a elementos transcendentes à obra, como a vida do autor. É neste sentido que ele causa problema à recepção.

Nesta relação entre escritor e os mass media, podemos relacioná-la ao problema do escritor, como homem público que toma suas obras para comentá-las: quando Michel Houellebecq escritor evidenciado pela mídia francesa e tomado como um verdadeiro homem público promove o lançamento de seu livro La possibilite d'une île em 2005, sua figura iluminada pela luz da cultura atrapalha a recepção do livro, e ao mesmo tempo, promove a venda de seus exemplares.

Paradoxo curioso no seio da relação entre os mass media e a literatura. $\mathrm{O}$ autor promove a venda de seus livros, obviamente, usando a força de seu nome, de seu estilo, e de sua personalidade. Ele assim o consegue por estar em evidência, por estar sob o foco da luz da mídia. Por que ele pode vir a causar um problema à recepção de sua obra? Pelo simples fato de que a captura da personalidade do escritor, executada pela mídia, coloca por demais em evidência este que escreve, seus pensamentos, sua personalidade. Isto gera muitos comentários pela imprensa especializada que tenta resenhar e dissecar a obra para o suposto leitor, usando a imagem do autor como alicerce de seus argumentos. Contudo, o mais interessante é que este movimento se interpõe entre o leitor e o livro, cons- 
truindo uma gama de elementos explicativos que direcionam ainda mais a leitura, e ao mesmo tempo, bloqueiam a ressonância leitora, tornando o livro uma obra ilegível, antes mesmo de ser comprada.

Em L'Entretien infini, Blanchot (1969) salienta esta questão controversa do papel do crítico literário e do movimento de captura da literatura, executado por seu trabalho que, ao mesmo tempo, esclarece a obra e a despotencializa. "O crítico está aí para se interpor entre livro e leitor. Ele representa as decisões e as vias da cultura. [...] Ele diz o que se deve ler e como se deve ler, tornando finalmente a leitura inútil” (BLANCHOT, 1969, p. 466).

O crítico se apresenta entre a leitura e o texto, por tentar direcionar a apreensão e a hierarquização das obras literárias. Para entendermos melhor este problema nos valeremos de um caso de recepção, em que o livro passou para segundo plano, devido às querelas, suscitadas na imprensa especializada: o caso Rushdie.

Kundera (1993), em Les Testaments Trahis, evidencia a polêmica em torno do livro Versos Satânicos de Salman Rushdie (1989) e mostra como a cultura e a crítica literária de cunho jornalístico, principalmente, se interpôs entre a obra de Rushdie e a apreciação do leitor, dando mais importância ao acontecimento do Fatwa (sentença de morte), imposto ao escritor indiano, pelo Ayatollah Ruhollah Khomeini no dia 14 de Fevereiro de 1989 e suas conseqüências, do que a própria obra em si.

Este livro de Rushdie (1989) trata da história de dois indianos: Gibrieel Farishta o grande ator do cinema indiano e Saladin Chamcha um intérprete de vozes de comerciais ingleses, "o homem das mil vozes" que após o seqüestro de seu vôo para Londres sofreram um acidente. Em uma das cenas mais fantásticas deste livro, os dois depois de caírem do céu sobre a costa inglesa, saindo ilesos do terrível incidente, se transformam em duas figuras que passam a representar a luta eterna entre o bem e o mal. Gibreel se torna um anjo e Chamcha uma espécie de demônio, se tornando os dois inimigos.

Deste acontecimento, se sucedem inúmeros eventos hilários e trágicos que colocam em xeque questões relativas às sociedades ocidental e oriental. No entanto, Ayattollah Khomeini decreta a sentença de morte do escritor, alegando que o texto seria um ato deliberado de blasfêmia contra o Islã, fomentando o abandono da fé islâmica. Esta acusação trata-se de um corte interpretativo dos problemas levantados pela obra, dando excessiva importância a uma dimensão que justamente ironiza algumas convicções da religião islâmica e trata com irreverência a figura do profeta Maomé.

A crítica foi impulsionada pela importância das querelas relacionadas aos problemas de vida e morte, e aos direitos de expressão. Este movimento de tomar a obra literária, como objeto de informação, para entender a atualidade do problema relativo à polêmica da obra e da relação desta com a pena de morte, transformou a obra em um mero corpo delito de um crime de blasfêmia e de fomento ao abandono da religião islâmica. Deixa-se de observar a capacidade humorística da análise da existência contemporânea feita pela obra para se de- 
bruçar sobre a sua atualidade e a questão da morte. A imprensa, dando mais importância a estas questões, mesmo que inocentemente, despotencializou a obra, tornando-a muito conhecida antes mesmo de ser experimentada. Poderíamos dizer que o livro Versos Satânicos ficou em evidência pelos motivos errados quando se trata de uma obra literária. A obra foi vaporizada pela iminência do problema de vida e morte do escritor. Neste caso, a obra desapareceu por trás da imagem polêmica do escritor criminoso.

Esta captura da obra mediante o trabalho árduo da crítica jornalística, defendendo de um lado o autor e, de outro, a própria religião, despotencializou, na teia explicativa da obra, a recepção do livro. É óbvio que não serão todos os leitores que serão levados a ler seguindo as querelas em que os críticos tanto se ateram. Não é disso que se trata aqui. O que queremos apontar é que a crítica exercida, desta maneira, oblitera o espaço de ressonância ${ }^{2}$, devido a seu excesso de sapiência, já que o acolhimento leitor se caracteriza por sua ignorância. A importância dada aos elementos transcendentes e prévios à experiência da obra, a torna muitas vezes ilegível.

A crítica literária pode, desta maneira, congelar as vias de ressonância da leitura literária com suas explicações que visam a direcioná-la, contendo seus movimentos criativos.

É curioso observarmos, como o aspecto institucional da cultura, certa espécie de crítica literária e o mercado se aliam para promover a absorção das obras, despotencializando seu caráter transgressivo e a tornando mais palatável às normas da sociedade, através de uma "pasteurização da transgressão".

Em uma entrevista de 1970, intitulada "Loucura, literatura, sociedade", Foucault (1999) afirma que a burguesia e o capitalismo têm um alto poder de adaptação e absorção. Ele salienta então, que devido a este poder, a literatura foi absorvida nos interstícios do capitalismo, normatizando-a e, assim, dando-lhe uma funcionalidade.

A cultura absorve a literatura através de seus conceitos obra, obra-prima e autoria e com sua aliança com o capitalismo utiliza estes mesmos conceitos como operadores de mercado moedas de valor no trato da mercadoria. Estes conceitos seriam então moedas de troca e, é justamente por isso que são tão valorizados na dinâmica cultural e mercadológica relativa aos livros.

O mercado se utiliza então destes conceitos implementados pela cultura como índices de seu trabalho de promoção da obra. Deste modo, a catalogação das obras literárias no universo unificado e iluminado da cultura é metabolizado nas vias do consumo.

Daí, pensarmos que há um movimento reducionista da experiência literária, através do enrijecimento conceitual da autoria e da obra, por parte dos mecanismos de captura, usados pela cultura e pelo comércio, tomando-os como índices explicativos e operadores de venda. 
Como afirmamos no início do artigo, a crítica literária teria um cunho transcendente, pois disseca os elementos da experiência, destilando os componentes explicativos da obra. No entanto, ela não teria uma forma totalmente coercitiva e restritora como poderíamos pensar de antemão. A crítica também sofre da mesma condição da linguagem: a condição de estar entre automatismos e a liberdade.

Jouve (2002) afirma que a inscrição da obra literária por si só em um gênero e em um lugar na instituição literária direciona a apropriação desta pelo público leitor. Ele ainda aponta que o papel das introduções e dos comentários gerais da obra que a prefaciam têm o intuito de "explicar porque e como se deve ler" a obra apresentada.

Contudo, salienta que a análise com sua sede de verdade e de compreensão não pode esgotar todas as formas de apreensões possíveis da obra. Daí, a característica importante da liberdade leitora.

Todavia, a crítica literária é uma atividade que em certo aspecto tenta murar a liberdade possível da experiência leitora. Devido a esta atividade coercitiva que exercem, os críticos receberam vários insultos e demonstrações de desprezo por parte de escritores.

Partindo desta idéia, Sartre (1948, p. 33) apresenta uma imagem muito interessante em relação à figura do crítico literário, em seu livro Qu'est-ce que la littérature?: "É necessário lembrarmos que a maioria dos críticos são homens que não tiveram muita sorte e que, no momento em que iriam entrar em desespero, acharam um pequeno lugar tranqüilo de guardião de cemitério".

"Guardião de cemitério" é uma interessante imagem sobre o trabalho crítico por vários motivos: (1) os conceitos de obra e autoria são componentes fechados explicativos, que muito se assemelham a catacumbas do sentido; (2) as convicções teóricas e interpretativas que visam a sobrepujar a experiência com suas práticas de verdade e monopólio de sentido calam a proliferação de sentido decorrente do contato com as obras literárias; (3) o trabalho do crítico pode estar direcionado a textos de autores realmente mortos, que por este motivo obviamente não podem se contrapor à apropriação imprópria de sua obra; (4) como os sentidos são congelados pelas práticas interpretativas, o crítico seria uma espécie de guardião destas práticas de imposição da boa leitura, um guardião dos monopólios do sentido, da verdade e das convicções teóricas.

Em se tratando da relação do crítico com os monopólios de sentido e das práticas de verdade sobre o objeto literário, podemos tomar a discussão estabelecida entre Pierre Bourdieu e Roger Chartier (2001), no debate "A leitura: uma prática cultural".

Chartier (BOURDIEU; CHARTIER, 2001), neste debate, coloca questões importantes sobre o trabalho da crítica literária, indicando que as leituras são plurais, mas que sofrem as tensões produzidas pelos "protocolos da leitura". A pergunta que Chartier levanta é a seguinte: 
E essa leitura plural que identificamos como realidade e como instrumento de análise, não a negamos também, de um certo ponto de vista, ao estabelecer o que deve ser a justa leitura dos textos, que é reencontrar a posição do clérigo que dá a correta interpretação da Escritura? (BOURDIEU; CHARTIER, 2001, p. 242).

A partir desta questão, Bourdieu (BOURDIEU; CHARTIER, 2001) analisa o problema relativo ao estabelecimento do justo sentido das obras, através do trabalho dos intelectuais. Ele aponta como os intelectuais trabalham em um embate contínuo que pressupõe a necessidade de construir "o monopólio da leitura legítima". (BOURDIEU; CHARTIER, 2001, p. 242)

Esta forma de trabalho que captura as obras para usá-las, como "instrumentos de poder", trata-se de estabelecer o que deve ser lido e como deve a leitura ser conduzida. Bourdieu (BOURDIEU; CHARTIER, 2001, p. 243) observa que a verdadeira cartada do trabalho intelectual está na compreensão de que "o poder sobre o livro é o poder sobre o poder que exerce o livro".

Pelo meio da discussão com o público, Bourdieu (BOURDIEU; CHARTIER, 2001) afirma que existe realmente uma luta entre o monopólio da leitura legítima e a força de fuga do próprio monopólio, e aponta para o perigo do monopólio absoluto, por causar este, o silêncio irremediável da experiência leitora.

É por causa deste mesmo motivo que Sontag (1987), em Contra a interpretação, analisa o problema relativo à esfera transcendente interpretacional e sua relação com a produção de verdade de caráter reacionário que torna a obra literária algo sem a potência que tanto a caracteriza. "Proust, Joyce, Faulkner, Rilke, Lawrence, Gide, poderíamos continuar citando um autor após o outro, é interminável a lista daqueles em torno dos quais se formaram espessas incrustações de interpretação" (SONTAG, 1987, p. 17).

"Incrustações de interpretações", curiosa imagem que nos serve para mostrar como a interpretação se cola às outras esferas imanentes à experiência, solapando e escondendo, atrás de crostas, a obra como espaço de ressonância. Estas incrustações são caracterizadas pelo excesso de sapiência e pela vontade de verdade já salientada.

Sontag (1987) argumenta que a crítica pode ser uma atividade tanto libertadora estando do lado de uma propagação ressonante que toma a obra como um espaço aberto de potência criativa - como reacionária - despotencializando a obra e esmagando as ressonâncias subjetivas e as proliferações de sentido. Entretanto, ela acrescenta que a forma moderna da crítica literária estaria mais do lado deste último modo do que do primeiro. A crítica, segundo ela, devido ao seu componente reacionário no trato interpretativo, asfixia os interstícios da propagação ressonante do espaço literário. 
Ela pensa de uma maneira muito próxima à reflexão blanchotiana tecida em L'Entretien Infini (1969), em que o autor salienta que o comentário cala o espaço de ressonância do campo experiencial do ler, devido à vontade do comentário de ser uma palavra reveladora da verdade da obra, completando a obra e, tornando-a, desta maneira, muda, intransponível, sem potência e ilegível.

Neste livro, podemos entender como a compreensão da obra, que visa a acrescentar a ela uma revelação a completando, traz consigo o germe do mutismo. A compreensão e o comentário, ao invés de acolher a obra em um movimento, em que a ignorância e a ressonância estariam em jogo, apreendem a obra dentro de um processo transcendente à experiência que objetiva explicá-la, domá-la, através de suas ferramentas e categorias pré-estabelecidas. Este seria o perigo da interpretação: colocar na obra algo que não é da ordem da obra.

Para entendermos isso, poderíamos junto a Sartre (1948) apresentar uma das síndromes intelectuais do nosso tempo: a interpretose psicanalítica.

Se somos versados um pouco em psicanálise, nosso prazer é perfeito: nós explicaremos Le Contrat social pelo complexo de Édipo e L'Esprit des lois pelo complexo de inferioridade; isto é, nós gozaremos plenamente da superioridade reconhecida que os cães vivos têm sobre os leões mortos (SARTRE, 1948, p. 36).

Vemos aqui, que há um prazer na explicação. A compreensão de um texto, a partir de categorias pré-estabelecidas, que serviriam de lupas para enxergar aquilo que o leitor comum não enxergaria, podem cegar muito mais do que podemos imaginar. Como já assinalamos com Nietzsche, a explicação tem a ver com a tranqüilidade, ela faz apreendermos o desconhecido e o irredutível da arte a partir de teias conceituais que reduzem o irredutível a suas categorias, tomando o conhecido como parâmetro.

Este trecho de Sartre (1948) reverbera com sua outra expressão muito feliz já sublinhada aqui o "guardião de cemitério", quando ele aponta que a explicação e a compreensão são frutos do poder exercido pelos "cães vivos" contra os "leões mortos".

O exercício da compreensão e da explicação tenta domar todos os leões mortos e evanescentes da experiência literária, não só o escritor, evocado claramente nesta imagem sartreana. $\mathrm{O}$ aspecto mais reacionário da interpretação objetiva domar o escritor, o autor, o leitor e a obra, a partir de seus conceitos, para, conseqüentemente, calar o espaço de ressonância.

Até agora, marcamos que a cultura institucional é atravessada por uma força unificadora e enquadradora das obras literárias, que o comércio se apresenta como uma força pasteurizadora da transgressão e que, certo aspecto da crítica literária se mostra como uma força despotencializadora da leitura literária. 
Como havíamos indicado com Eagleton (1991), existe uma crítica literária que estaria mais associada às querelas internas à academia do que ao comércio. Estas críticas impõem seus modos de compreender a obra literária. Suas querelas barulhentas acerca do sentido da obra só produzem o silêncio no campo ressonante e, talvez mais do que os problemas levantados pela imprensa especializada.

Em seu livro sobre a teoria da literatura, Eagleton (1997) sublinha como as instituições teóricas que se amontoam em torno do objeto literário visam a manutenção de instrumentos de poder e de controle. Ele sugere que os literatos são "guardiões de um discurso" (EAGLETON, 1997, p. 277), expressão que coincide muito propriamente com os "guardiões de cemitério" de Sartre.

Assim, após analisar muito bem as teorias literárias ao longo de seu livro, Eagleton (1997, p. 269) as denuncia: "a grande maioria das teorias literárias delineadas neste livro ressaltaram, em lugar de desafiar, os pressupostos de poder".

As teorias literárias e seu processo de captura da literatura constroem e, ao mesmo tempo, fiscalizam os instrumentos discursivos de poder sobre o objeto literário. Eagleton (1997) sublinha o caráter policialesco deste aspecto da interpretação e da sistematização da literatura, apontando que as relações de poder entre a instituição acadêmico-literária e a sociedade se entrelaçam numa dinâmica que: (1) fiscaliza a escrita, ao determinar o que deve ser taxado de literário ou não; (2) delega as autoridades do discurso acadêmico, ao definir os guardiões do discurso que terão como tarefa a definição e a preservação deste discurso de poder sobre a literatura e; (3) classifica os usuários competentes ou não do discurso sobre o objeto literário. Neste caso, vemos como este aspecto reacionário se articula de forma a se assemelhar a uma polícia da ordem dos discursos e dos livros.

Para entendermos este movimento de captura, podemos nos lembrar do que Kundera (1993) afirma sobre a literatura, em Les Testaments Trahis. Ele indica que a literatura tem como questão primordial a existência humana, manifestando-a através de problematizações que colocam nossas convicções sociais e individuais em xeque, mediante a dinâmica dos personagens.

Eagleton (1997), em sua denúncia da dimensão política da crítica, mostra de forma sucinta como ela se vale de conceitos, para obliterar e absorver os elementos questionadores da literatura. Deste modo, ele sublinha que a crítica teria uma natureza oposta à própria forma da literatura de se apresentar como questionamento difuso das convicções sociais.

Sempre ouvimos dizer que a literatura está vitalmente relacionada com as situações existenciais do homem: que ela é antes concreta do que abstrata, apresenta a vida em toda a sua rica variedade, e rejeita a investigação conceitual estéril, preferindo o sentimento e o gosto de se estar vivo. Paradoxalmente, a história da moderna teoria literária é a narrativa do afastamento dessas realidades, e da aproximação de uma gama aparentemente interminável de alternativas: o poema em si, a sociedade orgânica, as verdades eternas, a 
imaginação, a estrutura da mente humana, o mito, a linguagem e assim por diante (EAGLETON, 1997, p. 269-270).

É como se a crítica construísse anteparos que obstruíssem o encontro entre o leitor e a obra literária. Através da maquinaria explicativa, ela captura a literatura, tornando aquilo que ela não é. A crítica, em sua tentativa de controlar o sentido do texto, acaba por apresentar um controle sobre o corpo do leitor. Desta maneira, com Eagleton (1997), poderíamos afirmar que as mitologias críticas são aquelas que explicam à obra literária por movimentos que nos distanciam dos verdadeiros problemas existenciais contidos nela.

No entanto, a crítica literária também sofre da mesma condição da linguagem, mesmo sendo ela fruto de um movimento transcendente à experiência: a condição de ser atravessada por forças coercitivas e criativas.

Portanto, será que é possível uma crítica libertadora que acolha os paradoxos da leitura e, se apresente como uma crítica que fosse fruto da propagação e, por conseqüência, do contágio?

Em “Linguagem e literatura”, Foucault (2000) aposta em uma possível resposta positiva. Ele indica que a literatura se caracteriza por ser uma "linguagem ao infinito", e conseqüentemente, as maneiras de manifestar idéias acerca dela, também estariam do lado de uma "linguagem ao infinito". Mas ele salienta que a crítica seria segunda em relação à experiência escrita. Assim sendo, a crítica seria transcendente à experiência, como já frisamos.

Nesta conferência de 1964, Foucault (2000) argumenta que há uma multiplicação de atos críticos que percorrem disciplinas e artes variadas e, inversamente, a esta proliferação, o fenômeno de desaparecimento da figura do homo criticus como os franceses de seu tempo assim o compreendiam: um homem que influenciado por uma postura que remonta a de Sainte-Beuve, analisa criticamente o objeto literário à luz de elementos históricos, biográficos e exteriores à obra literária.

É curioso, como o tom esperançoso, em que Foucault (2000) se reporta às vicissitudes da crítica literária, se aproxima da virulência do texto Barthesiano "A morte do autor". Enquanto Barthes (1984) denuncia a figura do autor e do crítico, como travas do texto, Foucault (2000) anuncia o desaparecimento deste último.

Neste texto, Foucault (2000) assinala que a crítica, como instituição judicativa que se quer detentora da melhor leitura, perdeu sua força em seu tempo. É interessante, como este desaparecimento do crítico soa um pouco impreciso se pensarmos que quatro anos depois, Barthes (1984), ainda denunciaria o trabalho deste.

No entanto, Foucault (2000) faz uma interessante análise da dinâmica da crítica, apontando sua possibilidade de liberação, a partir de atos críticos que fogem as dimensões comuns à teoria literária.

Ele sublinha que a literatura seria o espaço em que a linguagem se redobra ao infinito, em sua relação com o vazio da morte. Assim sendo, a crítica seria a análise do que há de repetível no seio da literatura. 
Ele ainda salienta que os conceitos críticos estão ligados, comumente, a uma contextualização temporal do texto literário, compreendendo a literatura, a partir de uma "mitologia temporal da linguagem" (FOUCAULT, 2000, p. 169). Daí, as questões que circundam os problemas da origem e da intenção serem tão importantes para esta forma de pensar a obra.

Sua denúncia contra a crítica, afirma a importância de entender a obra literária, como um espaço, para não recair nestes mitos ligados à temporalidade, relativos à intencionalidade e à origem.

Ele e Barthes se aproximam pela aposta de que os atos críticos, fugindo de suas características comuns de coerção e organização dos estímulos literários, parecem se proliferar, se propagar através de uma escrita que se distribui em romances, poemas, reflexões e filosofias.

É como se ela fosse uma análise menor, no sentido que Deleuze e Guattari (1975) a pensam no seu livro sobre Kafka: uma análise que não levaria em conta arquétipos, associações livres e estruturas. Esta análise levaria a teoria literária a uma espécie de libertação, podendo ser observados nos atos críticos que reverberam na própria arte e na filosofia.

Ousaríamos dizer que estas reverberações apontam para uma crítica que não quer ser compreendida através de conceitos coercitivos que determinam a leitura legítima do texto literário, mas atos críticos que, ao pensar junto a literatura e ao ser levados por sua reflexão profusa, pensam de forma a colocar as próprias convicções de uma leitura legítima em xeque.

Obviamente, que estas reverberações críticas, transformadas em escritos, são mais raras ou mais difíceis de detectar do que imaginamos. No entanto, gostaríamos apenas de sublinhar que pode haver uma dimensão da interpretação que não sirva para os desígnios policialescos da cultura, do mercado e da própria crítica em suas tentativas de unificação, pasteurização, sistematização e explicação da obra literária.

\footnotetext{
Notas

${ }^{1}$ Em nossa tese de doutorado, Escrita e leitura: a produção de subjetividade na experiência literária (ALMEIDA, 2007), tratamos do caráter ambivalente e paradoxal da linguagem, indicando que ela comporta, ao mesmo tempo, formas de automatismos, hábitos linguageiros e de ordem, assim como de criações, liberdades e rebeldia. Esta característica reflete a própria condição humana e, por conseguinte, engloba a literatura e suas formas de captura e apreensão. Observamos, deste modo, que na linguagem existem vetores de criação e de aprisionamento. Como a linguagem, tanto a cultura, quanto a crítica literária, são atravessados por este paradoxo. No entanto, neste primeiro momento do presente artigo, analisaremos os usos reacionários da cultura e da critica literária em seu movimento institucionalizante e totalizante, para depois apontarmos novas vias associadas aos vetores de criação.

${ }^{2}$ A leitura literária é uma experiência intensa que se constitui como um espaço imanente de ressonância, em que elementos subjetivos e de sentido, a partir do contato com as forças ativas e reativas do campo experiencial, se entrechocam em seu encontro com a linguagem. $\mathrm{O}$ espaço de ressonância caracteriza a experiência total do ler (ALMEIDA, 2007).
} 


\section{REFERÊNCIAS}

ALMEIDA, L. P. Escrita e Leitura: a produção de subjetividade na experiência literária. 2007. Tese (Doutorado)-Departamento de Psicologia, Pontifícia Universidade Católica do Rio de Janeiro. Rio de Janeiro, 2007.

BARTHES, R. A morte do autor. In: . O Rumor da língua. São Paulo:

Brasiliense, 1984. p. 65-70.

BLANCHOT, M. L'Entretien Infini. Paris: Gallimard, 1969. . O espaço literário. Rio de Janeiro: Rocco, 1987.

BOURDIEU, P.; CHARTIER, R. A leitura: uma prática cultural - debate entre Pierre Bourdieu e Roger Chartier. In: BOURDIEU, P.; BRESSON, F.; CHARTIER, R. (Org.). Práticas da leitura. São Paulo: Estação Liberdade, 2001. p. 229-253.

BRUNN, A. L'auteur, textes choisis \& présentés par Alain Brunn. Paris: GF Flammarion, 2001.

DELEUZE, G.; GUATTARI, F. Kafka: pour une littérature mineure. Paris: Minuit, 1975.

EAGLETON, T. A função da crítica. São Paulo: M. Fontes, 1991.

. Teoria da literatura: uma introdução. São Paulo: M. Fontes, 1997.

FOUCAULT, M. Loucura, Literatura, Sociedade. In: . Problematização do Sujeito: Psicologia, Psiquiatria e Psicanálise. Rio de Janeiro: Forense Universitária, 1999. p. 210-134. Coleção Ditos e Escritos, v. I.

. Linguagem e literatura. In: MACHADO, R. Foucault, a filosofia e a literatura. Rio de Janeiro: J. Zahar, 2000. p. 137-174.

O Que é um Autor? In: . Estética: Literatura e Pintura, Música e

Cinema. Rio de Janeiro: Forense Universitária, 2001. p. 264-298. Coleção Ditos e Escritos, v. III.

GOULEMOT, J. M. Da leitura como produção de sentidos. In: CHARTIER, R. (Org.) Práticas da leitura. 2. ed. São Paulo: Estação Liberdade, 2001. p. 107-116.

HOUELLEBECQ, M. La Possibilite d'une île. Paris: Fayard, 2005.

JOUVE, V. A leitura. São Paulo: Unesp, 2002. 
KUNDERA, M. L'art du roman. Paris: Gallimard, 1986.

. Les Testaments trahis. Paris: Gallimard, 1993.

NIETZSCHE, F. Crepúsculo dos ídolos: ou como se filosofa com o martelo. São Paulo: Cia. das letras, 2006.

RUSHDIE, S. Les versets sataniques. Paris: Plon, 1989.

SARTRE, J. P. Qu'est-ce que la littérature? Paris: Gallimard, 1948.

SONTAG, S. Contra a interpretação. Porto Alegre: L\&PM, 1987.

Recebido em: abril de 2007

Aceito em: novembro de 2008 
